הี

\section{Beam Loss Monitor System for the SSC}

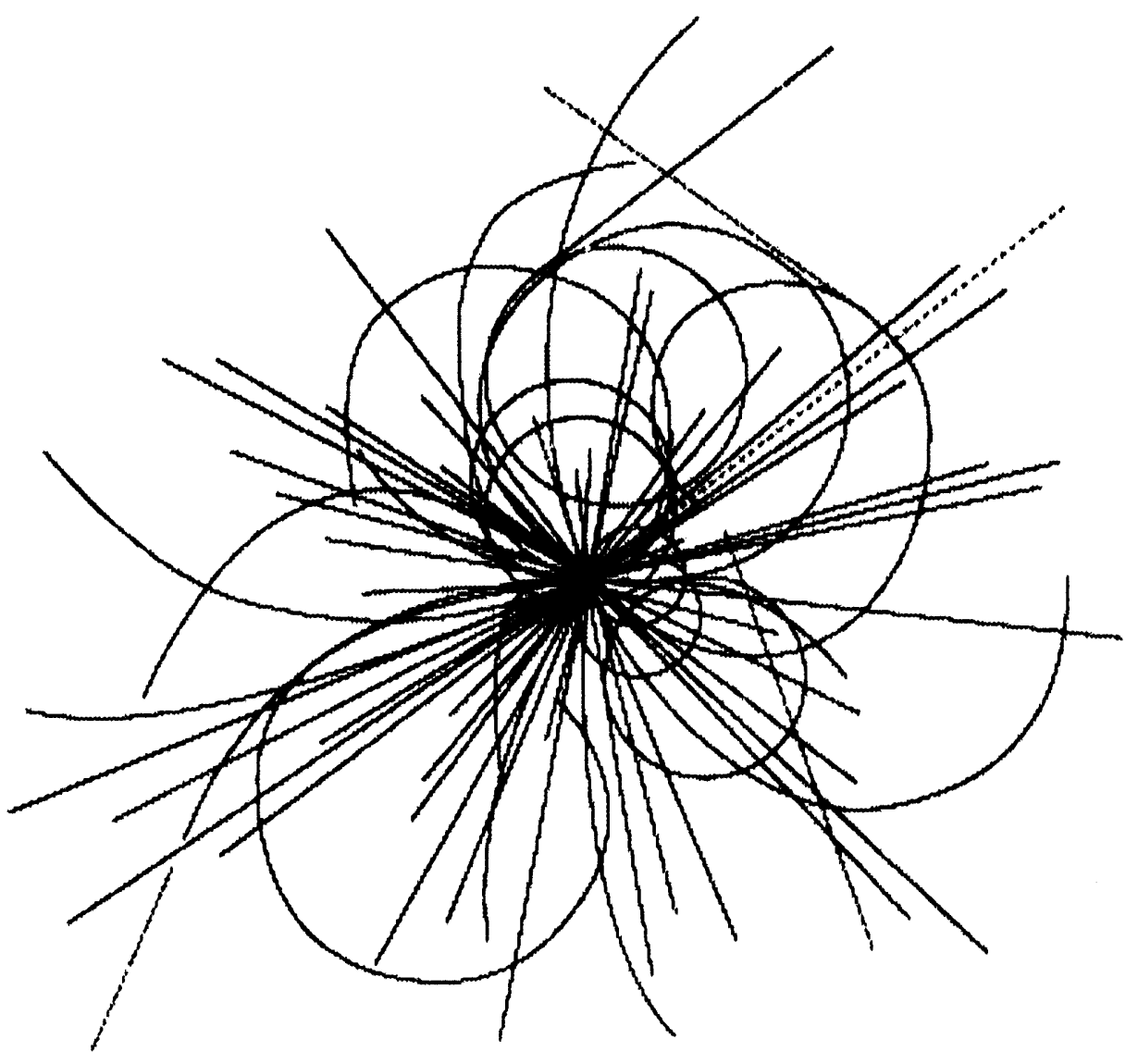

\section{Superconducting Super Collider Laboratory}

SSCL-Preprint-523

October 1993

Distribution Category: 414

R. Johnson

N. Mokhov

BECEIVED NOV 051990

OSTI 


\section{Disclaimer Notice}

This report was prepared as an account of work sponsored by an agency of the United States Govemment. Netther the United States Government or any agency thereol, nor any of their omployees, makes any warranty, uxpress or imptiad, or cesumes any logal liability or responsibitity for the eccuracy, completeness, or usefulness of any intormation, apparalus, product, or process dieclosed, or represents that the use would not infringe privately owned rights. Reference herein to any specitic commerclal product, process, or service by Irade name, tradernark, manufacturer, or otherwise, does not necescarily constifute or imply the endorsement, recommendation, or favoring by the Unted States Government or any acency thereot. The viaws and opinions of authors expressed herein do not necessarily state or reflect those of the United States Govemment or any agency thereof.

Superconductirg Super Collider Laboratory is an equal opportunity einployer. 
SSCL-Preprint-523

\title{
Beam Loss Monitor System for the SSC
}

\author{
R. Johnson and N. Mokhov \\ Superconducting Super Collider Laboratory ${ }^{\dagger}$ \\ 2550 Beckleymeade Ave. \\ Dallas, TX 75237
}

October 1993

"Presented at the Beam Instrumentation Workshop on October 20-23, 1993, in Santa Fe, New Mexico.

† Operated by the Universities Research Association, Inc., for the U.S. Department of Energy under Contract

No. DE-AC35-89ER40486. 


\title{
BEAM LOSS MONITOR SYSTEM FOR THE SSC
}

\author{
R.G. Jehuson and N.V. Mokhov \\ Superconducting Super Collider Laboratory ${ }^{*}$ \\ 2550 Beckleymeade Ave. \\ Dallas, TX 75237
}

\begin{abstract}
At full intensity the energy contained in each beam of the Superconducting Super Collider (SSC) is $400 \mathrm{MJ}$. The loss of a small fraction of that beam has the potential to cause magnet quenches or even severe damage to Collider components. To help protect the machine a sensitive and reliable beam loss monitor (BLM) system must be designed and built. In fact, BLM systems will be needed for all the accelerators of the SSC. The BLM system requirements for each of these accelerators will be discussed, but emphasis will be placed on the Collider. The discussion will include the preliminary design of BLM systems, the considerations that led to these designs, the calculations that were performed in development of the designs, and the problems that remain to be solved. A major tool in the design process has been a series of Monte Carlo calculations that were used to estimate beam loss distributions for the Collider arcs, the interaction regions, and the west utility region. These calculations were also used to study the fluence as a function of energy, the particle content, and the dose rate at selected positions. Detailed considerations such as detector spacing and sensitivity, loss fluctuations, reliability, and maintainability will be discussed. The proposed preliminary BLM system design for the Collider uses a radiation-hard, solid-state ionization detector and fast analog-to-digital conversion. Details of this design and relevant options will be discussed.
\end{abstract}

\section{INTRODUCTION}

The conceptual design of the Superconducting Super Collider (SSC) includes beam loss monitors (BLM) for all the accelerators in the chain. ${ }^{1}$ Table I lists some of the parameters of the SSC accelerators, including the number of BLMs. As can be inferred from this table, the BLM subsystem must encompass a large range of primary proton energies, and as is the case for many systems in the SSC the sheer numbers are daunting.

The primary purpose of the BLM system is to protect equipment from damage due to loss of protons from the beam. This is especially critical for the superconducting machines (High Energy Booster (HEB) and Collider rings), where excessive losses may induce magnet quenches. Although the magnets are designed to handle quenches, operation will be severely affected. Higher beam loss can induce excessive residual radioactivity, produce immediate damage from heating, and produce long-term damage from radiation. In order to provide complete protection, BLMs are approximately uniformly placed around each accelerator at places where the beam will scrape first,

\footnotetext{
* Operated by the Universities Research Association for the U.S. Department of
} Energy under Contract No. DE-AC35-89ER40486. 
i.e., at the quadrupoles. Thus the number of BLMs is in general set by the number of half cells.

BLMs are sensitive to the beam periphery, while the beam position monitors (BPM) are sensitive to the beam centroid. Consequently, the BLMs may provide the first indication of large emittance growth, a large beam halo, mistuning of focusing elements, etc.

In the remaining sections of this report the requirements set for the BLM systems will be discussed, and elements of systems satisfying these requirements will be presented. Much of the discussion will be centered on the Collider rings, where the requirements on the BLM system are the most stringent.

Table I. SSC Accelerator Parameters.

\begin{tabular}{|c|c|c|c|c|c|}
\hline Parameter & Linac & LEB & MEB & HEB & Collider \\
\hline Injection Energy & $35 \mathrm{keV}$ & $600 \mathrm{MeV}$ & $11.1 \mathrm{GeV}$ & $200 \mathrm{GeV}$ & $2 \mathrm{TeV}$ \\
\hline Extraction Energy & $600 \mathrm{MeV}$ & $11.1 \mathrm{GeV}$ & $200 \mathrm{GeV}$ & $2 \mathrm{TeV}$ & $20 \mathrm{TeV}$ \\
\hline $\begin{array}{l}\text { Circumference/ } \\
\text { Length }\end{array}$ & $148.2 \mathrm{~m}$ & $570 \mathrm{~m}$ & $3.960 \mathrm{~km}$ & $10.80 \mathrm{~km}$ & $87.12 \mathrm{~km}$ \\
\hline $\begin{array}{l}\text { Harmonic } \\
\text { Number }\end{array}$ & - & 114 & 792 & 2160 & $17424 \times 6$ \\
\hline Particles/Bunch ${ }^{a}$ & - & $\frac{1-}{5 \times 10^{10}}$ & $1-5 \times 10^{10}$ & $1-5 \times 10^{10}$ & $\begin{array}{l}0.75 \times \\
10^{10}\end{array}$ \\
\hline Total Particles ${ }^{a}$ & - & $5 \stackrel{1-}{5 \times 10^{12}}$ & $\begin{array}{l}0.8- \\
4 \times 10^{13}\end{array}$ & $\begin{array}{l}0.2- \\
1 \times 10^{14}\end{array}$ & $1.3 \times 10^{14}$ \\
\hline Rotation Time & - & $\begin{array}{l}2.3- \\
1.8 \mu \mathrm{s}\end{array}$ & $13.2 \mu \mathrm{s}$ & $36.0 \mu \mathrm{s}$ & $290 \mu \mathrm{s}$ \\
\hline Cycle Time $^{a}$ & $0.1 \mathrm{~s}$ & $0.1 \mathrm{~s}$ & $3-4 s$ & $4.3 \mathrm{~min}$ & - \\
\hline Mono/Bipolar & - & Mono & Mono & $\mathrm{Bi}$ & 2 Rings \\
\hline $\begin{array}{l}\text { Superconducting/ } \\
\text { Normal }\end{array}$ & Normal & Normal & Normal & $\mathrm{SC}$ & $\mathrm{SC}$ \\
\hline Peak Field & - & $1.2 \mathrm{~T}$ & $1.7 \mathrm{~T}$ & $6.7 \mathrm{~T}$ & $6.6 \mathrm{~T}$ \\
\hline No. of BLMs & 32 & 9ب9 & $206+$ & $636+$ & $1936+$ \\
\hline
\end{tabular}

${ }^{a}$ Collider-test beam operation.

\section{GENERAi, REQUIREMENTS}

Since there are more than 2500 BLMis spread over a linear distance of more than $100 \mathrm{~km}$, the BLMs and their electronics must require little or no maintenance. The expected life of the detectors should be at or beyond the expected lifetime of the accelerators, $25 \mathrm{yr}$. Any calibrations should be implemented through the control system. The 
detectors and electronics should perform diagnostics automatically on power up and continuously keep track of critical parameters. The ability to remotely mask out of the system any detector that is not working properly should be provided.

The BLM system performs a vital function for the accelerators, and thus its reliability must be very high. However, detectors will break down. In this regard the possibility of placing detectors in the cryostat has been rejected because it would decrease reliability and make replacement of defective detectors very difficult. Also, if the detectors are placed outside the cryostat, they can be easily repositioned. A method of ensuring system reliability is to provide redundancy. Where a detector performs a critical function, a back-up (with perhaps reduced effectiveness) should be available.

The prototypical detector used in the conceptual design study was the gas ionization chamber ${ }^{2}$ developed for the Fermi National Accelerator Laboratory (FNAL) Tevatron and used extensively for the other accelerators at FNAL. This detector has many desirable properties for application as a BLM. It is compact and rugged, requires little or no maintenance, has a predictable response with small sensitivity to variations in high voltage, has very low leakage current, and is relatively inexpensive. However, this detector has a rather low sensitivity, i.e., $70 \mathrm{nC} / \mathrm{rad}$. The lower limits to the response are a factor of 100 less sensitive than that required for the SSC superconducting magnets. (For the same amount of energy deposited in the coils, less radiation is seen outside the SSC magnets as compared to the Tevatron magnets.) In order to increase the sensitivity, several possibilities are being considered: (1) Increase the volume and/or pressure of the detector. (2) Develop a detector of similar size operating in the proportional regime. However, it is more difficult to design a proportional counter with the required longevity. (3) Add a preamplifier to the detector. Charge-sensitive hybrid preamplifiers with demonstrated radiation hardness up to $10 \mathrm{Mrad}$ and $10^{13} \mathrm{n} / \mathrm{cm}^{2}$ are available. (4) Use solid-state ionization chambers. HERA has used Si-PIN diodes for this purpose. ${ }^{4}$ However, Si diodes are sensitive to radiation damage. GaAs strip detectors are being developed, ${ }^{5}$ but they have a relatively high leakage current for use as ionization chambers. There are several exotic solid-state materials, ${ }^{6,7}$ e.g., $\mathrm{HgI}_{2}, \mathrm{CdTe}$, and $\mathrm{PbI}_{2}$, that show promise as ionization detectors with low leakage current and good radiation hardness.

\section{SPECIFIC REQUIREMENTS}

\section{Linac}

The requirements that have been established for the Linac impose some unique properties on the BLM system because the Linac is unique in the accelerator chain. In terms of the response times of detectors, i.e., $\mu \mathrm{s}$, the Linac is the only accelerator for which the pulse structure of the beam is important. The Linac also spans the largest relative energy range, and of particular importance to the BLM detectors the energy starts near zero. Finally, since the secondary radiation from beam loss is directed forward, it is somewhat more difficult to detect in a linear as opposed to a circular accelerator.

For the lowest-energy part of the Linac the protons do not carry enough energy to produce radiation outside the accelerator structure. In fact, the lowest energy required for the BLM detectors is $13.6 \mathrm{MeV}$, i.e., at the end of DTL tank 1 , and here a relaxed sensitivity, $0.1 \%$ loss, is specified. From DTL tank $2(30 \mathrm{MeV})$ and above the required sensitivity is a $0.01 \%$ loss, where losses are defined for a detector $1.0 \mathrm{~m}$ from a point loss at a shallow angle.

At these low energies the major secondary radiation from beam loss will be neutrons. Consequently, to obtain sensitivity at these low primary energies some relax- 
ation of other requirements, such as longevity, may have to be made. To detect fast neutrons with high efficiency, a hydrogen-containing scintillator can be used. The choice is a plastic scintillator $(2.5 \mathrm{~cm}$ in diameter and $10 \mathrm{~cm}$ in length) coupled to a photomultiplier tube (PMT). This detector will require maintenance and periodic calibration and may have reduced longevity. However, there are only nine of these detectors.

From about $200 \mathrm{MeV}$ and above, the switch to an ionization chamber or a proportional counter can be made. These detectors will be able to meet the requirements above this energy. The exact choice of detector is loosely tied to the choice of detector for the higher-energy accelerators, with an interest in maintaining compatibility, i.e., choosing the same detector if possible.

The requirements for the Linac BLM system are listed in Table II.

Table II. Linac BLM Requirements.

\begin{tabular}{ll}
\hline \multicolumn{1}{c}{ Property } & \multicolumn{1}{c}{ Value } \\
\hline \multicolumn{1}{c}{$(\mathrm{E}>30 \mathrm{MeV})$} & $0.01 \%\left(1.5 \times 10^{9} \mathrm{p} / \mathrm{s}\right)$ \\
Sensitivity $(\mathrm{E}>13.6 \mathrm{MeV})$ & \multicolumn{1}{c}{$10^{4}$} \\
Dynamic Range & After each tank \\
Spacing-DTL & After each module \\
Spacing-CCL & $<10 \mu \mathrm{s}(1 \mu \mathrm{s}$ at $0.1 \%$ \\
Pulse Rise Time & sensitivity $)$ \\
\hline
\end{tabular}

\section{LEB and MEB}

The requirements for the Lower Energy Booster (LEB) and Medium Energy Booster (MEB) synchrotron rings are very similar. In general BLM detectors will be placed at each quadrupole magnet of the accelerator, i.e., where the beam envelope is at a maximum. For the proton energy range covered by these accelerators, the radiation generated by beam loss increases as $\mathrm{E}^{0.8}$. Here the $\mathrm{FNAL}$ ionization detector or equivalent will suffice. With a minimum response of $10 \mathrm{mrad} / \mathrm{s}$ for the $B L M$, the minimum loss rates are approximately $1.0 \times 10^{9} \mathrm{p} / \mathrm{s}$ to $1.0 \times 10^{7} \mathrm{p} / \mathrm{s}(1 \mathrm{~m}$ from a point loss at a shallow angle) from injection into the LEB to extraction from the MEB.

The BLM requirements for the LEB and MEB are shown in Table III.

Although losses have been expressed per unit time with the assumption that these are continuous losses, the opposite extreme of instantaneous losses can be considered. (This will become important for the cold machines where the quench characteristics depend on the loss time scale. A $\sim 0.1$-s integration time will equalize the BLM response to fast and slow loss quench characteristics.) The detector electronics have a $\sim 0.1$-s integration time built in. Consequently the instantaneous response of the detectors is ten times $(10 \times)$ more sensitive. 
Table III. LEB and MEB BLM Requirements.

\begin{tabular}{lll}
\hline \multicolumn{1}{c}{ Property } & \multicolumn{1}{c}{ LEE Value } & \multicolumn{1}{c}{ MEB Value } \\
\hline Sensitivity (Injection) & $1.0 \times 10^{9} \mathrm{p} / \mathrm{s}$ & $1.0 \times 10^{8} \mathrm{p} / \mathrm{s}$ \\
(Extraction) & $1.0 \times 10^{8} \mathrm{p} / \mathrm{s}$ & $1.0 \times 10^{7} \mathrm{p} / \mathrm{s}$ \\
Dynamic Range & $10 \mathrm{mrad} / \mathrm{s}-100 \mathrm{rad} / \mathrm{s}$ & $10 \mathrm{mrad} / \mathrm{s}-100 \mathrm{rad} / \mathrm{s}$ \\
Spacing & $\sim 6 \mathrm{~m}$ & $\sim 19 \mathrm{~m}$ \\
Pulse Rise Time & $<10 \mu \mathrm{s}$ & $<10 \mu \mathrm{s}$ \\
Integration Time & $100 \mathrm{~ms}$ & $100 \mathrm{~ms}$ \\
\hline
\end{tabular}

\section{HEB and Collider Rings}

The most severe requirement on the BLM system will be at the top energy of the collider rings $(20 \mathrm{TeV})$. At this energy the magnets are operating with the least margin, and the energy carried by each proton is, of course, a maximum. In Table IV the expected tolerable beam losses for a variety of effects are summarized. (Most of the discussion in this section refers to the Collider.)

Of prime importance in this table are the expected quench levels. For an instantaneous loss, i.e., no heat flow, $<1.0 \mathrm{~ms}$, the quench level depends on the reserve enthalpy in the superconducting coils. A correction for the fact that the maximum energy deposition in the coils (along the horizontal plane) is not where the maximum magnetic field occurs has been included in the value calculated. ${ }^{8}$ The quench level for a continuous loss depends on the cooling of the coils. The value listed is based on calculation and extrapolation from measurements and calculations for the Tevatron magnets. ${ }^{9}$

Table IV. Projected Beam Losses for the Collider Rings.

\begin{tabular}{|c|c|c|}
\hline Purpose & Beam Loss & Comments \\
\hline \multirow[t]{2}{*}{$\begin{array}{l}\text { Quench } \\
\text { Protection }\end{array}$} & $3 \times 10^{6} \mathrm{p} / \mathrm{m}-\mathrm{s}$ & Slow loss $(3 \mathrm{~mW} / \mathrm{g})$ \\
\hline & $3.5 \times 10^{6} \mathrm{p} / \mathrm{m}$ & Fast loss $(0.5 \mathrm{~mJ} / \mathrm{g})-$ Reserve Enthalpy \\
\hline $\begin{array}{l}\text { Radiation } \\
\text { Damage }\end{array}$ & $1 \times 10^{4} \mathrm{p} / \mathrm{m}-\mathrm{s}$ & Dose $<1000 \mathrm{Mrad}$ for $25 \mathrm{yr}$ \\
\hline \multirow[t]{2}{*}{ Cryogenics } & $10^{5} \mathrm{p} / \mathrm{m}-\mathrm{s}$ & Over a few magnets ( $<4 \mathrm{~W}$ per magnet) \\
\hline & $10^{4} \mathrm{p} / \mathrm{m}-\mathrm{s}$ & Over whole machine $(<0.4 \mathrm{~W}$ per magnet) \\
\hline $\begin{array}{l}\text { Radiation } \\
\text { Safety }\end{array}$ & $10^{4} \mathrm{p} / \mathrm{m}-\mathrm{s}$ & For both slow and accidental losses \\
\hline $\begin{array}{l}\text { Beam-Gas } \\
\text { Interaction }\end{array}$ & $4 \times 10^{3} \mathrm{p} / \mathrm{m}-\mathrm{s}$ & At design current and vacuum \\
\hline
\end{tabular}


Another slow response limit on beam loss is placed by the cooling capacity of the cryogenics system. The limits shown in Table IV apply to an overload in one sector, i.e., heating in a few magnets, and an overload of an entire ring. These limits are also important in deternining the radiation dose limits that need to be considered.

Calculation of the radiation dose (rate) outside the cryostat has been done using the MARS 12 high-energy hadron and electromagnetic cascade code. ${ }^{10}$ This code provides a detailed simulation in 3-D geometry, including the magnetic field, of the collider lattice for both rings. Beam loss has been simulated in three half standard cells $(270 \mathrm{~m})$ for the case of a continuous loss and an accidental loss at the beginning of a dipole. The results of such simulations for the Collider arcs are shown in Figure 1. The energy deposition at positions just outside the cryostat as a function of distance along the ring for a continuous loss has been calculated. Positioning a BLM on the horizontal plane at or near the downstream interconnect for each quadrupole is the most advantageous, and it leads to a dose rate of $0.1-0.3 \mathrm{mrad} / \mathrm{s}$ for a loss of $10^{4} \mathrm{p} / \mathrm{m}-\mathrm{s}$. For a fast beam loss at the beginning of a dipole, the maximum energy deposition is $6 \times 10^{-4} \mathrm{GeV} / \mathrm{g}$ per proton. For a loss of $10^{3} \mathrm{p}$ the dose is $0.01 \mathrm{mrad}$.

Initial SSC studies assumed a spacing of $30 \mathrm{~m}$ between detectors for the Collider. This spacing was based on providing nearly uniform coverage. The simulations indicate that a spacing of $15 \mathrm{~m}$ is actually needed to provide uniform coverage, i.e., the radiation from a point loss falls off an order of magnitude each $15 \mathrm{~m}$. Fortunately, by careful consideration of loss scenarios, it has been realized that uniform coverage should not be required. The actual spacing between detectors should be determined by where the beam envelope is a maximum, i.e., at the quadrupoles. Although knowledge of which ring is at fault is not required for abort purposes, it is proposed that a BLM be placed at the quadrupoles for each ring. These detectors can then provide increased reliability through redundancy, and they can provide more complete diagnostic information on which ring caused the abort.

Most of the requirements on the BLM system for the cold machines can be specified from the considerations of Table IV and the simulations described above. These requirements are listed in Table $\mathrm{V}$.

In order to achieve these requirements the preferred detector is a solid-state ionization detector, $\mathrm{HgI}_{2}$. A prototype detector with dimensions $20 \times 20 \times 3 \mathrm{~mm}^{3}$ has been acquired and tested. The calculated sensitivity is $18 \mu \mathrm{C} / \mathrm{rad}$. The measured pulse-rise time is about $2 \mu \mathrm{s}$ at a bias voltage of $+1.0 \mathrm{kV}$, and the noise is very small. Previous radiation damage testing has shown that this material is very damage-resistant. ${ }^{11,12}$ The primary question is whether the material will be available in sufficient quantity and at a reasonable cost.

Additional simulations of beam loss have been performed for the interaction regions and the utility region (the location of the beam scrapers and beam abort systems). These simulations are used to predict the pattern of loss longitudinally in the various beam line elements. The radial and azimuthal distribution of radiation at selected points can also be obtained. Finally, particle fluence and energy spectra can be predicted. These simulations will be used to help specify the placement of the BLMs and to predict their response under various loss situations. In these regions of the Collider, the BLM system becomes an important tool for tuning the machine in addition to its protective function. For example, the scrapers are used to remove beam halo, which in turn improves the signal-to-background ratio in the large detectors. As the scrapers are moved into the beam, the BLMs will provide information on the scraping rate. Also, since the scrapers will likely be the limiting aperture, any tuning problems may be made evident by increased beam loss at the scrapers. 

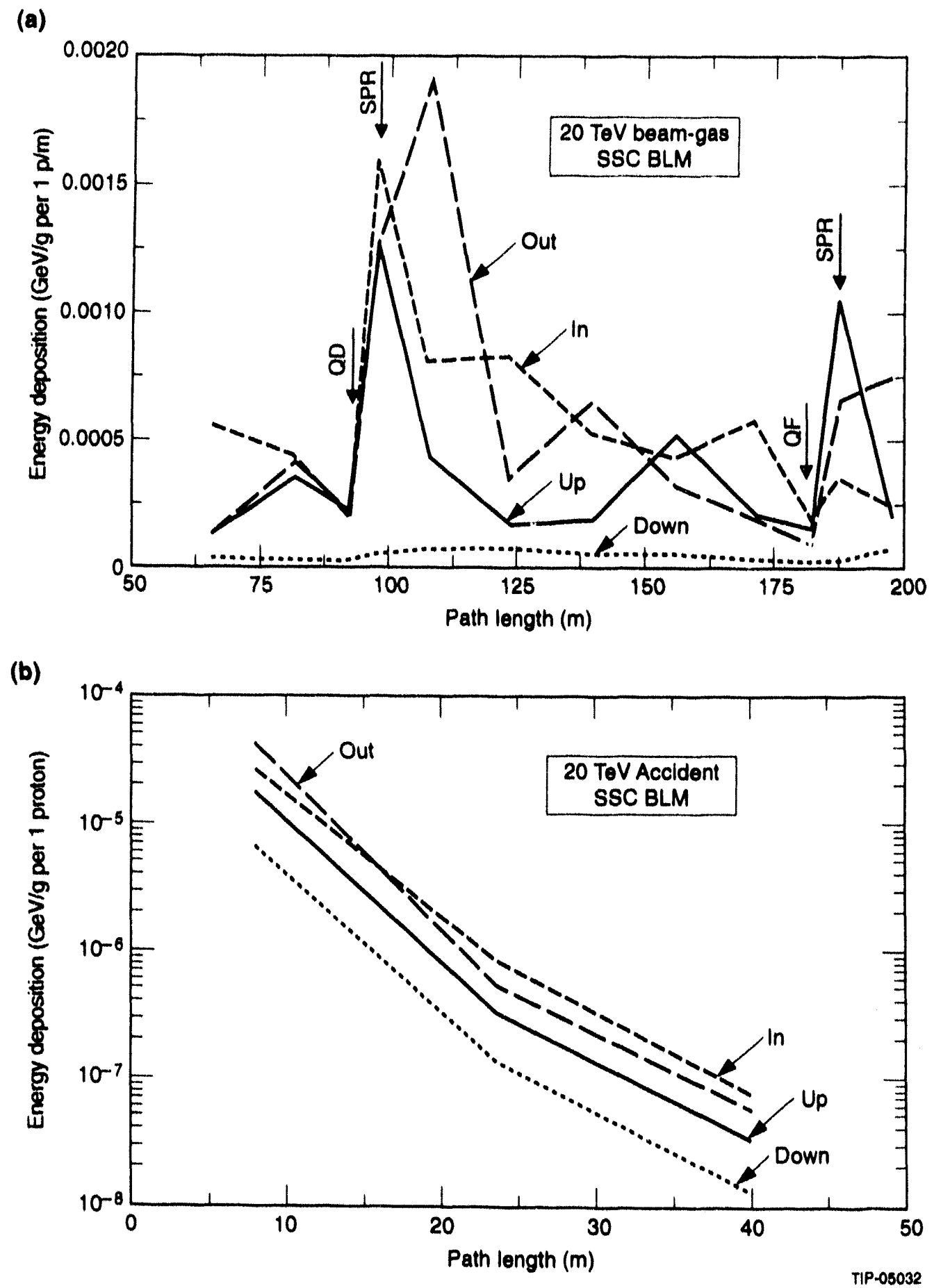

Figure 1. Energy deposition by (a) continuous and (b) instantaneous loss at the beginning of a dipole, averaged over each element. Positions are just outside the cryostat; in and out refer to the center of the ring. QF and QD are focusing and defocusing quadrupoles, and SPR is the spool piece. 
Table V. HEB and Collider Ring(s) BLM Requirements.

\begin{tabular}{lll}
\hline \multicolumn{1}{c}{ Property } & \multicolumn{1}{c}{ HEB Value } & \multicolumn{1}{c}{ Collider Value } \\
\hline Sensitivity (Continuous) & $1 \times 10^{6} \mathrm{p} / \mathrm{m}-\mathrm{s}$ & $1 \times 10^{5} \mathrm{p} / \mathrm{m}-\mathrm{s}$ \\
at Low E (Instantaneous) & $1 \times 10^{5} \mathrm{p} / \mathrm{p}$ & $1 \times 10^{4} \mathrm{p} / \mathrm{p}$ \\
Sensitivity (Continuous) & $1 \times 10^{5} \mathrm{p} / \mathrm{m}-\mathrm{s}$ & $1 \times 10^{4} \mathrm{p} / \mathrm{m}-\mathrm{s}$ \\
at High E (Instantaneous) & $1 \times 10^{4} \mathrm{p} / \mathrm{p}$ & $1 \times 10^{3} \mathrm{p} / \mathrm{p}$ \\
Dynamic Range & & \\
(Continuous) & $1.0 \mathrm{mrad} / \mathrm{s}-10.0 \mathrm{rad} / \mathrm{s}$ & $0.1 \mathrm{mrad} / \mathrm{s}-1.0 \mathrm{rad} / \mathrm{s}$ \\
(Instantaneous) & $0.1 \mathrm{mrad}-1.0 \mathrm{rad}$ & $0.01 \mathrm{mrad}-0.1 \mathrm{rad}$ \\
Spacing & $\sim 32.5 \mathrm{~m}$ & $\sim 90 \mathrm{~m}$ \\
Pulse Rise Time & $<10 \mu \mathrm{s}$ & $<10 \mu \mathrm{s}$ \\
Integration Time & $100 \mathrm{~ms}$ & $100 \mathrm{~ms}$ \\
\hline
\end{tabular}

${ }^{a}$ Distance between quadrupoles.

The low-beta quadrupoles in the interaction region must be closely monitored because they are being particularly hard hit by beam loss.

\section{ELECTRONICS}

A block diagram of the proposed electronics system is shown in Figure 2. A prototype of this system has been built and tested for the Linac BLM system. The detector is a radiation-damage-resistant plastic scintillator (3HF based) viewed by a nine-stage PMT. The fast integrator stretches the 40-ns anode pulse to $1.0 \mu \mathrm{s}$ and provides a times 10 charge gain. The fast integrator circuit performs very well. Offset is small, $\sim 0.1 \mathrm{mV}$, and stable; noise is less than $1 \mathrm{mV}$ peak to peak, and linearity is good.

In general, the fast integrator stretches the pulse so that a sampling ADC of moderate speed can follow the time development of the beam loss. Data will be digitized on a $0.5-\mu \mathrm{s}$ (for the Linac) to $10-\mu \mathrm{s}$ interval, stored, and integrated. At an approximately 0.1 -s time interval, data will be sent to the central control system. Locally the latest $32-\mathrm{k}$ data points would be retained and could be transferred to the central computer on request. The electronics system for the BLMs will be implemented in a standard format, VXI or VME. The former is preferred because it has been designed to handle analog signals, and it includes a $\pm 24-\mathrm{V}$ supply, electronic shielding, and larger board space. In fact, the digital portion of a BPM electronics board has been designed and a prototype board built ${ }^{13}$ in the VXI format. This board, with very few changes, will be the digital portion of a BLM electronics board (for the Linac at least). The board has four individual ADCs with $32 \mathrm{k}$ words of memory for each channel.

It is expected that the control system will monitor the status of the crates that contain the electronics. This monitoring would include over and under voltage on all the standard voltages, over temperature, reduced air flow, and crate control status. These status parameters should be read on a nearly continuous basis, i.e., $10 \mathrm{~Hz}$. In addition, a set of status and control registers is on each BLM board. These registers 
include the results of power-up tests, module identification, and default parameters that need to be read only after a restart. Other registers that contain the current status will need to be monitored on a continuous basis.

Since the BLM system provides machine protection, the abort channel is a separate system that, for the HEB and Collider rings, will be connected directly to the abort kickers. The design goal is to provide abort decisions in a time much less than that for a single turn. The warning and abort levels will be set in the same FPGA that contains the integration circuitry. Comparison at the dizital level should be sufficient and would not add additional circuitry.

In addition to the data acquisition board, detectors will require an HV bias supply. A design that provides eight channels of high voltage on a triple-width VME card has been produced. ${ }^{14} \mathrm{~A}$ version of the design could be modified for VXI.

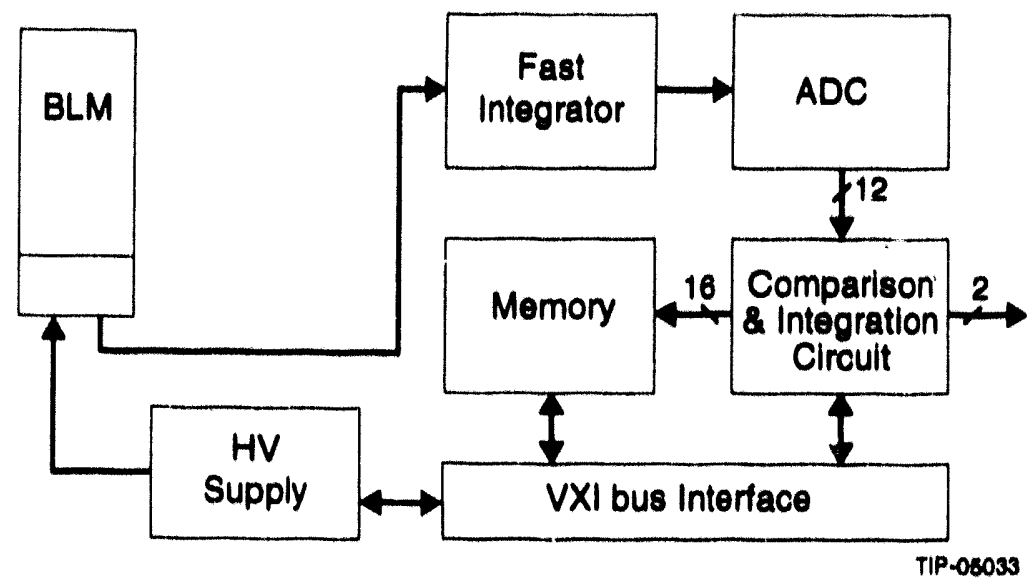

Figure 2. Electronics Block Diagram.

\section{SUMMARY}

Most of the requirements for the BLM system for the SSC accelerators have been established. Although the FNAL gas ionization chambers will be adequate for the accelerators up to the HEB (except for the low-energy portion of the Linac), the sensitivity needs to be increased by 100 for the superconducting machines. Several options for providing this increased sensitivity have been listed, and the preferred option indicated.

\section{ACKNOWLEDGEMENTS}

The authors wish to thank V.M. Gerrish and J.M. Markakis of EG\&G Energy Measurements, Inc., for the loan of several $\mathrm{HgI}_{2}$ detectors and for valuable discussions about the properties of these detectors. 


\section{REFERENCES}

1. Site-Specific Conceptual Design of the Superconducting Super Collider, eds. J.R. Sanford and D.M. Matthews (SSC Laboratory, Dallas, TX, 1990) SSCL-SR1056.

2. R.E. Shafer, R.E. Gerig, A.E. Baumbaugh, and C.R. Wegner, The Tevatron Beam Position and Beam Loss Monitoring Systems, International Conference on High Energy Accelerators, FNAL (1983) 609.

3. H.W. Kraner, J.A. Kierstead, P.W. Levy, S. Rescia, V. Radcka, and A. Stevens, Radiation Damage Studies on Hybrid Preamplifiers, private communication, 1992.

4. K. Wittenburg, Radiation Damage in PIN-Photodiodes, Nucl. Instrum. and Meth. A270 (1988) 56.

5. S.P. Beaumont, et al., Gallium Arsenide Microstrip Detectors for Charged Particles, submitted to Nucl. Instrum. and Meth. (1992).

6. J.S. Iwanczyk, Advances in Mercuric Iodide X-Ray Detectors and Low Noise Preamplification Systems, Nucl. Instrum. and Meth. A283 (1989) 208.

7. F. Olschner, J.C. Lund, K.S. Shah, and M.R. Squillante, New Semiconductor Materials for Radiation Detectors, ICFA Instrumentation Bull. 7 (1989) p. 9.

8. M.A. Maslov and N.V. Mokhov, On Tolerable Energy Deposition in Superconducting Magnet Windings at Pulse High Energy i'articles Irradiation, Proceedings of III ICFA, Protvino (1981) 3.

9. H. Edwards, C. Rode, and J. McCarthy, Measurements of Magnet Quench Levels Induced by Proton Beam Spray, IEEE Trans on Magnetics, MAG-13 (1977) 666.

10. N.V. Mokhov, The MARS10 Code System: Inclusive Simulation of Hadronic and Electromagnetic Cascades and Muon Transport (FNAL, Batavia, IL, 1989) FN509.

A.N. Kalinovskii, N.V. Mokhov, and Yu.P. Nikitin, Passage of High-Energy Particles through Matter (American Institute of Physics, New York, 1989).

11. B.E. Patt, R.C. Dolin, T.M. Devore, J.M. Markakis, J.S. Iwanczyk, N. Dorri, and J. Trombka, Radiation Damage Resistance in Mercuric Iodide X-Ray Detectors, Nucl. Instrum. and Meth. A299 (1990) 176.

12. F.D. Becchetti, R.S. Raymond, R.A. Ristinen, W.F. Schnepple, and C. Ortale, Mercuric Iodide $\left(\mathrm{HgI}_{2}\right)$ Semiconductor Devices as Charged Particle Detectors, Nucl. Instrum. and Meth. 213 (1983) 127.

13. Alan A. Jones, VXI Bus Beam Position Monitor Module, SSCL Internal Report, August 1992.

14. A.A. Jones, A New VME Based High Voltage Power Supply for Large Experiments, private communication, 1992. 
